\title{
Liberdade do Exercício da Advocacia: Normas de Acesso a Autos - Voto Divergente PCA 9387
}

Técio Lins e Silva

\section{PROCEDIMENTO DE CONTROLE ADMINISTRATIVO № 200710000009387}

RELATOR: Conselheiro JORGE ANTONIO MAURIQUE

REQUERENTE: ORDEM DOS ADVOGADOS DO BRASIL - SEÇÃO DO DISTRITO FEDERAL

INTERESSADO: IBANEIS ROCHA BARROS JUNIOR

REQUERIDO: SUPERIOR TRIBUNAL DE JUSTIÇA

ASSUNTO: NORMAS DE ACESSO A AUTOS

\section{VOTO DIVERGENTE}

Trata-se de matéria da maior relevância, pois envolve a liberdade do exercício da advocacia.

Basta ver que os recorrentes são o Conselho Federal e a Seção do Distrito Federal da Ordem dos Advogados do Brasil, igualmente se insurgindo contra decisão monocrática que, liminarmente, arquivou procedimento de controle administrativo, proposto pela Ordem dos Advogados do Brasil - Seção Distrito Federal, questionando ato administrativo do Superior Tribunal de Justiça, o qual, editando a Instrução Normativa nº 02/2006, inova na criação de regras para o acesso dos Advogados aos autos dos processos judiciais em curso naquela Corte, violando o Estatuto da Advocacia e da OAB, dispostos na Lei 8906/94.

Ao embasar a decisão que não conheceu do pedido e determinou o arquivamento do referido procedimento, o Ilustre Relator, Conselheiro Jorge Antônio 
Maurique, aduziu que o ato ora impugnado constitui matéria tipicamente jurisdicional, razão pela qual sua apreciação não estaria inserida nas hipóteses de atribuição do Conselho Nacional de Justiça.

Eis o âmago da matéria!

Data máxima vênia, entendo que o eminente Conselheiro Relator, nāo obstante o brilho habitual de suas decisões, nesta hipótese, deixou de considerar importantes características do ato impugnado, as quais conduzem, de modo inequívoco, à conclusão de que se trata de ato tipicamente administrativo, cujo controle da sua legalidade não só é atribuição deste Conselho Nacional de Justiça, como, antes de tudo, apresenta-se como uma das principais razões de sua existência.

Ora, sabe-se que administrar e julgar apresentam como traço comum justamente a faceta de serem formas de aplicar a lei preexistente. Entretanto, a distinção básica e inafastável reside em que, na função administrativa, aplica-se a lei de ofício perseguindo as finalidades instituídas pelo legislador, enquanto, na função jurisdicional, aplica-se a lei, por provocaçāo do interessado, ao caso concreto conflituoso. Assim, somente a inserção de certo ato como componente decisivo e indispensável num procedimento, tendente a solucionar em caráter definitivo um conflito, um litígio de interesses, configurará a presença de um ato jurisdicional.

Sobre o tema, dada a clareza e didática de sua exposição, cabe aqui colacionar as liçōes de um conterrâneo ilustre do Conselheiro Relator, o Eminente Ministro Athos Gusmão Carneiro, ${ }^{1}$ que, através de diversos critérios de natureza objetiva, traçou um elucidativo quadro distintivo entre o que se pode considerar ato jurisdicional e ato administrativo. Senão, vejamos:

\begin{tabular}{|l|l|l|}
\hline \multicolumn{1}{|c|}{ Ato jurisdicional } & \multicolumn{1}{|c|}{ Ato administrativo } \\
\hline $\begin{array}{l}\text { A atividade jurisdicional depende de "iniciati- } \\
\text { va do parte interessado", mediante o ajuiza- } \\
\text { mento da "açöo" (ubi non est actio ibi non est } \\
\text { jurisdictio). }\end{array}$ & $\begin{array}{l}\text { A atividade administrativa pode dispensar requeri- } \\
\text { mento do interessado, agindo, portanto "de oficio", }\end{array}$ \\
\hline $\begin{array}{l}\text { A "aplicoçōo do lei" a uma pretensão é o "ob- } \\
\text { jetivo", em si mesmo, da atividade jurisdicio- } \\
\text { nal; é a razão de ser da jurisdição. }\end{array}$ & $\begin{array}{l}\text { A administração, conquanto deva agir em confor- } \\
\text { midade com a lei, aplicando a lei, tem por "objetivo" } \\
\text { a promoçāo do "bem comum". }\end{array}$ \\
\hline $\begin{array}{l}\text { A atividade jurisdicional pressupōe como } \\
\text { causa um litígio, uma "lide" (ainda que virtual). } \\
\text { para cuja eliminação é aplicada a lei. }\end{array}$ & $\begin{array}{l}\text { A atividade administrativa visa satisfazer necessida- } \\
\text { des individuais e coletivas, não tendo por pressu- } \\
\text { posto a existência de uma lide entre partes. }\end{array}$ \\
\hline $\begin{array}{l}\text { A atividade jurisdicional reveste-se (segundo } \\
\text { Chiovenda) normalmente do caráter de ativi- } \\
\text { dade de "substituiçōo". }\end{array}$ & $\begin{array}{l}\text { A atividade administrativa é "atividade primária" ou } \\
\text { originária. }\end{array}$ \\
\hline
\end{tabular}

1 Carneiro, Athos Gusmāo. Jurisdiçāo e Competência. 15. ed. Editora Saraiva. p. 26. 


\begin{tabular}{|l|l|l|}
\hline \multicolumn{1}{|c|}{ Ato jurisdicional } & \multicolumn{1}{|c|}{ Ato administrativo } \\
\hline $\begin{array}{l}\text { A jurisdição atua sempre "processualmente", } \\
\text { sob as regras da dualidode de partes e do } \\
\text { controditório. para apreciar conflitos "alheios" } \\
\text { (o juiz julga in re cliena). }\end{array}$ & $\begin{array}{l}\text { A administração geralmente age informaimente, } \\
\text { embora deva com freqüência organizar procedi- } \\
\text { mentos. com ritos previstos em lei, para prover } \\
\text { acerca de certos assuntos em que a própria admi- } \\
\text { nistraçāo é parte interessada (prover in re suo) } .\end{array}$ \\
\hline $\begin{array}{l}\text { O ato jurisdicional de composição da lide } \\
\text { contença de mérito) adquire a "outoridade de } \\
\text { imutáveis. }\end{array}$ & $\begin{array}{l}\text { As decisões administrativas podem apenas precluir } \\
\text { no âmbito da administração (não admitem recurso } \\
\text { administrativo), mas estão sujeitas, sem exceção, } \\
\text { quanto à suo legolidade, ao reexame pelo judiciá- } \\
\text { rio. }\end{array}$ \\
\hline
\end{tabular}

Aplicando tais distinções à presente hipótese, percebe-se que, ao editar a referida Instrução Normativa, o Superior Tribunal de Justiça não atuou por provocação de nenhuma parte em ação judicial, nem buscou a aplicação da lei a um conflito concreto e preexistente, no qual é obrigatória a aplicação das regras processuais relativas à dualidade das partes. Ao contrário, agiu de ofício para disciplinar a aplicação de lei preexistente, ${ }^{2}$ visando realizar o "bem comum" e atuando como parte interessada na consecução de tal objetivo.

Assim, diante de todas essas circunstâncias, forçoso reconhecer que a edição da mencionada Instrução Normativa constitui verdadeiro ato administrativo, cuja legalidade pode - e deve - ser analisada por este Conselho Nacional de Justiça.

Partindo, então, ao mérito da questão, percebe-se que, pela própria natureza do ato impugnado, o Superior Tribunal de Justiça, em verdade, realizou, normatização administrativa acerca de matéria já tratada em lei, mais especificamente na Lei no 9.806/94, que corresponde ao Estatuto da OAB e da Advocacia.

Não é preciso tecer maiores considerações sobre os limites impostos a tal normatização administrativa, uma vez que, dada a hierarquia entre as normas, afigura-se evidente que seus termos não podem contrariar nem extrapolar os direitos e obrigaçōes contidos na Constituição e nas leis ordinárias.

Como se vê, essa conclusão, das mais basilares no nosso ordenamento jurídico, impõe que a análise acerca da legalidade da referida Instruçāo Normativa seja feita à luz do disposto na Constituição Federal e na Lei no 8.906/94.

Para tanto, vejamos os dispositivos pertinentes insertos nos diplomas acima referidos:

Constituição Federal:

Art. $5^{\circ} \mathrm{LV}$ - aos litigantes, em processo judicial ou administrativo, e aos acusados em geral são assegurados o contraditório e ampla defesa, com os meios e recursos a ela inerentes; 
Art. 133. O advogado é indispensável à administração da justiça, sendo inviolável por seus atos e manifestações no exercício da profissão, nos limites da lei.

Lei $n^{2} 8.906 / 94$ :

Art. $7^{\circ}$ São direitos do advogado:

XIII - examinar, em qualquer órgão dos Poderes Judiciário e Legislativo, ou da Administraçāo Pública em geral, autos de processos findos ou em andamento, mesmo sem procuração, quando não estejam sujeitos a sigilo, assegurada a obtenção de cópias, podendo tomar apontamentos;

$X V$ - ter vista dos processos judiciais ou administrativos de qualquer natureza, em cartório ou na repartição competente, ou retirá-los pelos prazos legais;

$X V I$ - retirar autos de processos findos, mesmo sem procuração, pelo prazo de dez dias;

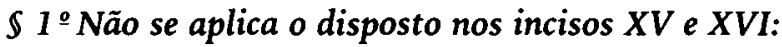

1) aos processos sob regime de segredo de justiça;

2) quando existirem nos autos documentos originais de dificil restauração ou ocorrer circunstância relevante que justifique a permanência dos autos no cartório, secretaria ou repartição, reconhecida pela autoridade em despacho motivado, proferido de oficio, mediante representação ou a requerimento da parte interessada;

Da análise dos preceitos acima transcritos, conclui-se que a regra é a permissão de acesso e obtenção de cópias dos autos pelos advogados, mesmo aqueles sem procuração, direito este que somente poderá ser restringido diante da circunstância, excepcional, de estarem os mesmos sob regime de segredo de justiça.

Extrapolando os limites impostos pela Constituição e pela Lei Federal $\mathbf{n}^{\circ}$ 8.906/94, a Instrução Normativa $\mathrm{n}^{0}$ 02/2006 do Superior Tribunal de Justiça, instituiu os seguintes dispositivos:

\section{"FORNECIMENTO DE CÓPIAS E DE CERTIDÕES}

Art. $2^{\circ}$ As solicitaçóes de cópias por advogado regularmente constituido nos autos serão atendidas pelas Coordenadorias.

$\$ 2$ Os processos criminais de competência da Corte Especial e os que correrem em segredo de justiça, bem como aqueles indicados pelo Relator, só poderão ser consultados e fotocopiados pelas partes ou pelos procuradores constituídos nos autos.

$S^{3^{\circ}} \mathrm{O}$ Relator apreciará, em face de petiçáo fundamentada, o pedido de extração de cópias quando o advogado não tiver procuração nos autos, salvo determinação em contrário.

$54^{\circ}$ As Coordenadorias somente poderão fornecer cópias de decisōes monocráticas e colegiadas, antes de sua publicą̧ão no Diário da Justiça, a 
advogado com procuração nos autos e desde que autorizado pelos Relatores."

Em suma, o que tais preceitos estabelecem é que i) Advogados sem procuração, mesmo em processos não submetidos a segredo de justiça, só terão acesso aos autos quando, após requerimento escrito nesse sentido, forem autorizados pelo relator do processo; ii) os processos em trâmite perante a Corte Especial e os porventura indicados pelo Relator só poderão ser fotocopiados por Advogados neles constituídos e iii) a cópia de todas as decisōes monocráticas e colegiadas, - parte indiscutivelmente integrante do processo judicial, antes de sua publicação no Diário Oficial, só poderāo ser fornecidas a Advogados com procuração nos autos.

Todas essas inovadoras restrições encontram-se na contramão da legislação federal em vigor, a qual, conforme já se ressaltou, só permite a restrição do acesso e obtenção de cópia de autos quando se tratar de processo em segredo de justiça e o Advogado nele não estiver constituído ou, ainda, quando, apenas no tocante à obtenção de cópias, "existirem nos autos documentos originais de difíil restauração ou ocorrer circunstância relevante que justifique a permanência dos autos no cartório, secretaria ou repartição", hipótese em que tal restrição precisará ser "reconhecida pela autoridade em despacho motivado, proferido de oficio, mediante representação ou a requerimento da parte interessada" (art. $7^{\circ}, \$ 1^{\circ}, \mathrm{n}^{\circ} 2$ 2, Lei 8906/94).

Sendo assim, não há como negar que os dispositivos destacados da Instrução Normativa ora impugnada extrapolam, e muito, os limites impostos pela legislação federal, sobretudo porque importam em graves restrições a direitos anteriormente conferidos por norma de natureza diversa e de envergadura hierárquica superior.

Diante de todas as considerações aqui desenvolvidas, entendo que, com exceção do $\$ 1^{2}$ - que impede a obtenção de cópia dos autos que se encontrarem conclusos - todos os dispositivos do capítulo "FORNECIMENTO DE CÓPIAS E DE CERTIDÕES", da Instrução Normativa $n^{\circ}$ 02/2006 do STJ, usurpam direitos legalmente constituídos aos Advogados e importam em sensivel violação da sua atividade profissional, razão pela qual entendo que deve ser acolhido o pedido de desconstituição do ato administrativo sub censura.

É como me pronuncio, manifestando as minhas homenagens ao ilustre Relator, de quem ouso divergir nesse tema, sem embargo de minha constante e reconhecida admiração pelo brilho de sua inteligência.

Sala das Sessões, 06 de novembro de 2007. 